\title{
Atypical Deep Cerebral Vein Thrombosis with Hemorrhagic Venous Infarction in a Patient Positive for COVID-19
}

\author{
(D) L. Chougar, (D) B. Mathon, (D) N. Weiss, (D) V. Degos, and (D) N. Shor
}

\section{ABSTRACT}

SUMMARY: There is growing evidence that Severe Acute Respiratory Syndrome coronavirus 2 (SARS-CoV-2) has a neurotropic and neuroinvasive potential. In particular, neurologic complications associated with the infection by SARS-CoV-2 include strokes that may result from a dysregulated inflammatory response to the infection. We report an atypical deep cerebral vein thrombosis complicated with hemorrhagic venous infarction in a patient positive for SARS-CoV-2 with no risk factors for thrombosis.

ABBREVIATIONS: COVID-19 = coronavirus disease 2019; SARS-CoV-2 = Severe Acute Respiratory Syndrome coronavirus 2; RT-PCR = Reverse TranscriptasePolymerase Chain Reaction; CSF = cerebrospinal fluid

S nce the coronavirus disease 2019 (COVID-19) outbreak in December 2019 in China, an increasing number of patients infected with the Severe Acute Respiratory Syndrome coronavirus 2 (SARS-CoV-2) have been presenting with neurologic symptoms either simultaneously with the flulike syndrome or during the course of a SARS-CoV-2-associated pneumonia. Neurologic manifestations range from mild to severe, including impaired consciousness, acute cerebrovascular disease, and seizures. ${ }^{1}$ A presumptive case of COVID-19-associated acute necrotizing hemorrhagic encephalopathy has been recently reported. ${ }^{2}$ Most commonly, an increased risk of cerebrovascular complications has been associated with the COVID-19. ${ }^{3-5}$ Herein, we report an extensive deep cerebral vein thrombosis with hemorrhagic venous infarction in a patient positive for SARS-CoV-2 with no known risk factor for thrombosis.

\section{CASE DESCRIPTION}

A 72-year-old man with no relevant medical history presented with sudden left hemiparesis, altered mental status, and refractory

Received April 20, 2020; accepted after revision May 14.

From the Service de Neuroradiologie (L.C., N.S.), Service de Neurochirurgie (B.M.), Anesthesia, Critical Care and Perioperative Medicine (V.D.), Médecine Intensive Réanimation Neurologique (N.W.), Hôpital Pitié-Salpêtrière, Assistance PubliqueHôpitaux de Paris, Paris, France; Sorbonne Université (L.C., B.M., N.W., V.D., N.S.) Paris, France; and Institut du Cerveau et de la Moelle épinière (L.C., B.M.), National Institute for Health and Medical Research U 1127, Centre National de la Recherche Scientifique, Une Unité Mixte de Recherche, 7225, Sorbonne Université, Pierre and Marie Curie University, Une Unité Mixte de Recherche S 1127, Centre National de la Recherche Scientifique, Une Unité Mixte de Recherche 7225, Paris, France.

Please address correspondence to Lydia Chougar, MD, Service de Neuroradiologie, APHP, Hôpital Pitié-Salpêtrière, Boulevard de l'Hôpital, 75651 Paris Cedex 13, France; e-mail: chougar.lydia@gmail.com

- Indicates open access to non-subscribers at www.ajnr.org

http://dx.doi.org/10.3174/ajnr.A6642 status epilepticus. Retrospectively, the patient's family reported mild respiratory symptoms a few days earlier.

The nasopharyngeal swab was positive for SARS-CoV-2 using the reverse transcriptase polymerase chain reaction (RT-PCR) and negative for influenza $\mathrm{A}$ and $\mathrm{B}$ viruses and adenoviruses. Cerebrospinal fluid (CSF) analysis showed an increased red blood cell count $\left(500 / \mathrm{mm}^{3}\right)$ due to traumatic lumbar puncture, and apleocytosis (30 white blood cells/ $\mathrm{mm}^{3}$ ). The results of the RT-PCR including the SARS-CoV-2, herpes simplex viruses 1 and 2, varicella zoster virus, cytomegalovirus, and Epstein-Barr virus as well as the bacterial culture, were negative in the CSF.

Noncontrast CT revealed a right deep hemispheric hypodensity with some hyperdense areas, involving the thalamus, basal ganglia, internal capsule and splenium of the corpus callosum, and the deep white matter. A subtle hypodensity within the left thalamus could also be seen. These abnormalities caused a moderate mass effect on the midline structures. Among the scattered areas of parenchymal hemorrhage, spontaneous hyperdensity was detected within the internal cerebral veins and the vein of Galen. A CT venogram showed no opacification of these veins, confirming the diagnosis of acute deep cerebral vein thrombosis complicated by hemorrhagic venous infarction (Fig 1).

MR imaging performed ten hours later showed marked progression of the vasogenic edema, extending to the right cerebral peduncle and the pons, and increased hemorrhagic changes involving the lateral ventricles. Contrast-enhanced images evidenced a lack of enhancement within the deep brain regions, corresponding to necrotic areas associated with the venous infarction. Associated involvement of the basal veins of Rosenthal and thalamostriate veins was suspected on susceptibility-weighting images. 


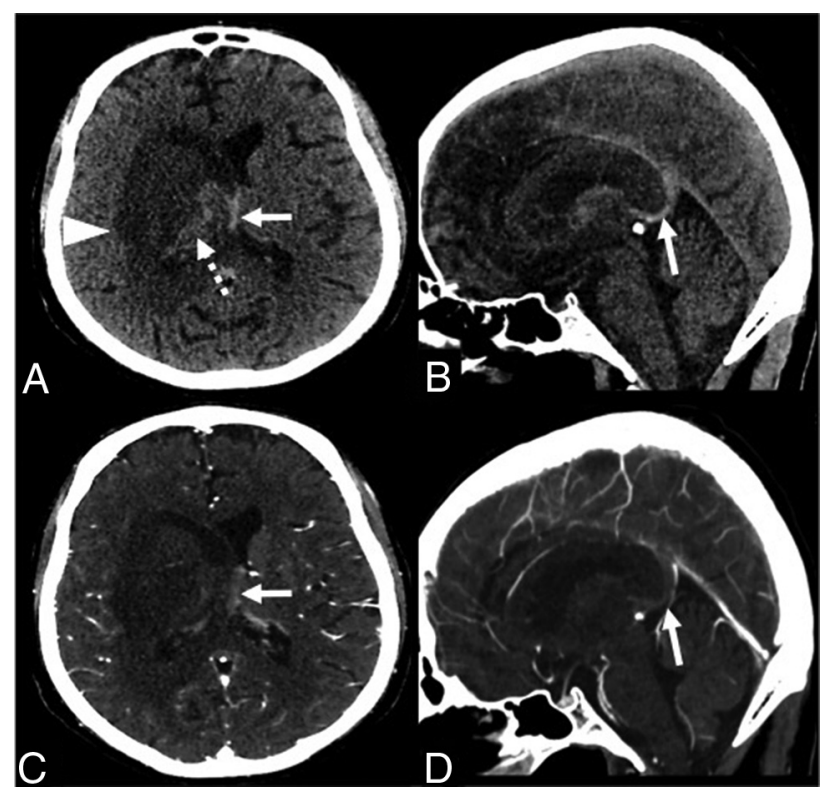

FIG 1. Axial $(A$ and $C)$ and parasagittal $(B$ and $D) C T$ images without (upper row) and with contrast injection (lower row) show a right deep hypodensity involving the gray and white matter ( $A$, arrowhead), with areas of hemorrhage ( $A$, dashed arrow). The internal cerebral veins are shifted to the left and appear spontaneously and $D$, arrows). hyperdense ( $A$ and $B$, arrows), without noticeable opacification ( $C$

The medullary veins were dilated, due to venous engorgement. Curvilinear gadolinium enhancement along the medullary veins was visible within the FLAIR hyperintensities in the centrum semiovale, corresponding to the opacification of the small-vessel lumen and/or enhancement of its perivascular spaces (Fig 2).

Tests for thrombophilia were negative. The patient was transferred to an intensive care unit where an endotracheal intubation was performed and curative anticoagulation and antiepileptic therapy were initiated. Four days after the admission, the patient evolved toward brain death.

\section{DISCUSSION}

It is increasingly recognized that COVID-19 is associated with a prothrombotic state. It has been established that patients with COVID-19 hospitalized in intensive care units are at higher risk of venous and arterial thrombotic events despite prophylactic or curative anticoagulation. ${ }^{3,4}$ More recently, a higher incidence of arterial stroke has provided evidence of central nervous system involvement associated with the COVID-19. ${ }^{3-5}$

Respiratory viruses including coronaviruses are known for their neurotropic and neuroinvasive potential, damaging the central nervous system through an immune-mediated mechanism in susceptible subjects and/or direct damage to nerve cells following viral invasion. ${ }^{6}$ Studies conducted on lung fibroblasts and umbilical vein endothelial cells, which are a classic in vitro model for brain endothelial cells, have demonstrated that respiratory viruses are able to induce epithelial damage as well as platelet

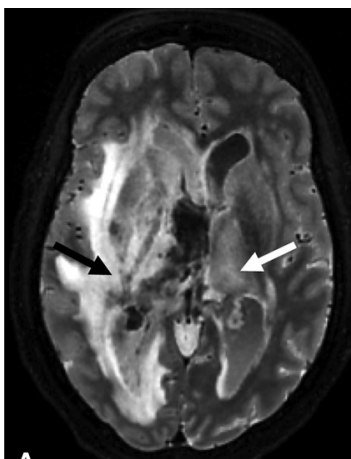

A

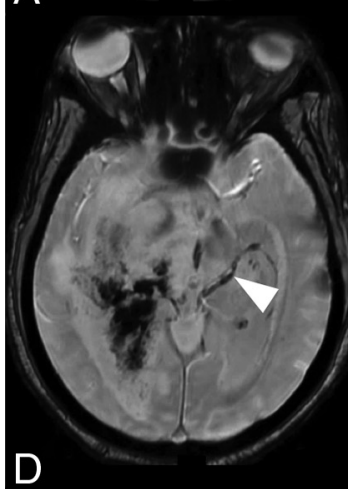

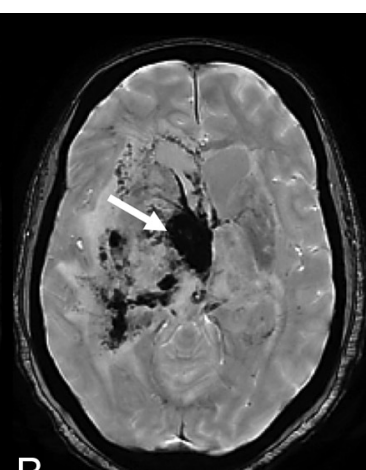

B

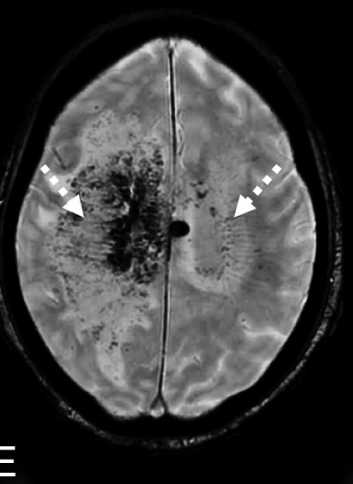

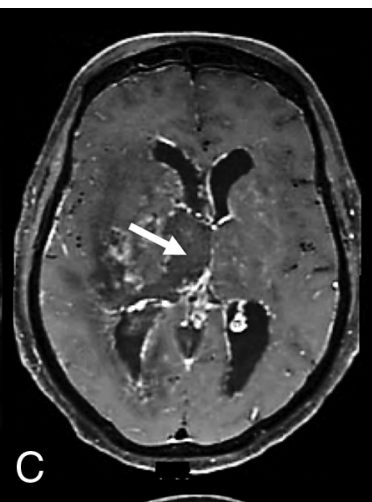

C

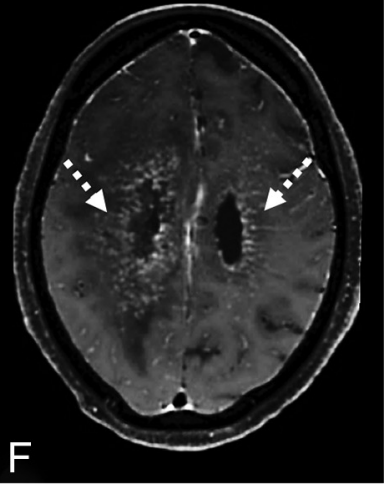

FIG 2. Axial FLAIR $(A)$, SWI $(B, D$, and $E)$, and postcontrast T1-weighted MR images ( $C$ and $F$ ). There is an extensive asymmetrical vasogenic edema including the deep gray and white matters $(A$, arrows), with hemorrhage ( $B$, arrow) and necrotic areas ( $C$, arrow), corresponding to a hemorrhagic venous infarction. The basal veins of Rosenthal also appear involved on SWI ( $D$, arrowhead). The medullary veins are dilated (E, dashed arrows), with associated curvilinear gadolinium enhancement ( $F$, dashed arrows). and endothelial cell dysfunction. ${ }^{7}$ More specifically, the angiotensin-converting enzyme 2 is a cellular receptor for the Severe Acute Respiratory Syndrome coronavirus and the new coronavirus (SARSCoV-2), expressed by respiratory and caralso be found on the surface of brain endothelial cells and could be induced in neurons, reinforcing the hypothesis of potential brain damage caused by the infection. ${ }^{9}$ On the other hand, it has been suggested that the systemic inflammatory response syndrome seen in critically ill patients with COVID-19 may participate in the pathogenesis of vascular thrombosis through a dysregulated cytokine storm, without direct viral invasion or immune mediation. That massive inflammatory cascade may lead to reversible or irreversible end-organ dysfunction, including endothelial alterations and microthrombosis. ${ }^{3-5}$

This case of deep cerebral vein thrombosis with hemorrhagic venous infarction in a patient positive for COVID-19 showed some uncommon imaging features, including asymmetric deep brain involvement, the presence of large necrotic diac endothelial cells. ${ }^{8}$ This receptor can 
areas within the venous infarction, and the extent of the intraventricular hemorrhage. Furthermore, there was striking and atypical curvilinear enhancement along the medullary veins in association with white matter signal abnormalities. This peculiar feature has been described in vasculopathies such as posterior reversible encephalopathy syndrome and Susac syndrome and in disorders with angiocentric infiltrates, especially neurolupus, neurosarcoidosis, ${ }^{10}$ and immune reconstitution inflammatory syndrome in patients infected with HIV. ${ }^{10,11}$ These findings raise the hypothesis of a potential vascular and/or perivascular involvement associated with the deep vein thrombosis.

\section{ACKNOWLEDGMENTS}

We wish to thank Stéphane Lehéricy, Samia Belkacem, Mickaël Luscher, Delphine Leclercq and Nadya Pyatigorskaya for their valuable contribution.

Disclosures: Nicolas Weiss_UNRELATED: Consultancy: Medday Pharmaceuticals.

\section{REFERENCES}

1. Mao L, Jin H Wang M, et al. Neurologic manifestations of hospitalized patients with coronavirus disease 2019 in Wuhan, China. JAMA Neurol 2020 Apr 10. [Epub ahead of print] CrossRef Medline

2. Poyiadji N, Shahin G, Noujaim D, et al. COVID-19-associated acute hemorrhagic necrotizing encephalopathy: CT and MRI features. Radiology 2020 Mar 31. [Epub ahead of print] CrossRef Medline
3. Helms J, Tacquard C, Severac F, et al; CRICS TRIGGERSEP Group (Clinical Research in Intensive Care and Sepsis Trial Group for Global Evaluation and Research in Sepsis). High risk of thrombosis in patients in severe SARS-CoV-2 infection: a multicenter prospective cohort study. Intensive Care Med 2020 May 4. [Epub ahead of print] CrossRef Medline

4. Klok FA, Kruip M, van der Meer NJ, et al. Incidence of thrombotic complications in critically ill ICU patients with COVID-19. Thromb Res 2020 Apr 10. [Epub ahead of print] CrossRef Medline

5. Asadi-Pooya AA, Simani L. Central nervous system manifestations of COVID-19: a systematic review. J Neurol Sci 2020;413:116832 CrossRef Medline

6. Desforges M, Le Coupanec A, Dubeau P, et al. Human coronaviruses and other respiratory viruses: underestimated opportunistic pathogens of the central nervous system? Viruses 2019;12:14 CrossRef Medline

7. Visseren FL, Bouwman JJ, Bouter KP, et al. Procoagulant activity of endothelial cells after infection with respiratory viruses. Thromb Haemost 2000;84:319-24 CrossRef

8. Yan R, Zhang Y, Li Y, et al. Structural basis for the recognition of SARS-CoV-2 by full-length human ACE2. Science 2020;367:144448 CrossRef Medline

9. Nath A. Neurologic complications of coronavirus infections. Neurology 2020;94:809-10 CrossRef Medline

10. Taieb G, Duran-Peña A, de Chamfleur NM, et al. Punctate and curvilinear gadolinium enhancing lesions in the brain: a practical approach. Neuroradiology 2016;58:221-35 CrossRef Medline

11. Lescure FX, Moulignier A, Savatovsky J, et al. CD8 encephalitis in HIV-infected patients receiving cART: a treatable entity. Clin Infect Dis 2013;57:101-08 CrossRef Medline 